\title{
Remoção do herbicida glifosato utilizando carvão ativado impregnado com compostos metálicos de prata e cobre para a melhoria da qualidade da água
}

\author{
Removal of the herbicide Glyphosate using activated carbon impregnated with \\ metallic compounds of silver and copper to improve water quality
}

\author{
Andressa Jenifer Rubio ${ }^{1}$, Rosângela Bergamasco ${ }^{2}$ e Natália Ueda Yamaguchi ${ }^{3}$ \\ ${ }^{1}$ Graduanda, Engenharia Ambiental e Sanitária, UNICESUMAR, Maringá, PR, Brasil \\ 2Docente, Engenharia Química, UEM, Maringá, PR, Brasil \\ ${ }^{2}$ Doutoranda, Engenharia Química, UEM, Maringá, PR, Brasil e Docente, Engenharia Ambiental e Sanitária, UNICESUMAR, \\ Maringá, PR, Brasil
}

\begin{abstract}
Resumo
Com a crescente utilização de diversos pesticidas na agricultura, incluindo o Glifosato que é o herbicida mais consumido mundialmente, há a necessidade de desenvolvimento de tratamentos de água diversificados e eficazes. Como tratamento alternativo, a remoção do glifosato da água pode ser obtida com a utilização do carvão ativado impregnado com metais para potencializar seus resultados. Portanto, o presente trabalho visou a remoção do herbicida glifosato por meio de um processo de adsorção utilizando o carvão ativado impregnado com prata e cobre $0,5 \%$ com o objetivo de aumentar a eficiência de adsorção quando comparado ao carvão ativado comercial. Observou-se que a remoção de glifosato é melhorada quando se utiliza a impregnação de compostos metálicos, sendo de $66,1 \%$ com o adsorvente GAC/AgCu e de apenas 21,1\% com GAC. Ainda são necessárias pesquisas mais aprofundadas relacionadas a caracterização e ensaios de adsorção para explicar melhor o mecanismo de adsorção que ocorre neste processo. Porém, pode-se concluir que o carvão ativado granular impregnado com prata e cobre 0,5\% desenvolvido no presente trabalho pode ser apontado como uma possível tecnologia para a melhoria na qualidade da água destinada ao consumo humano para a remoção do herbicida glifosato.
\end{abstract}

Palavras-chave: Carvão ativado; Cobre; Glifosato; Prata.

\begin{abstract}
With the increasing use of several pesticides in agriculture, including the Glyphosate which is the herbicide most widely consumed worldwide, there is a need for the development of diversified and effective water treatment, since glyphosate consumption can cause serious health problems on animals, humans and plants. As an alternative treatment, the removal of glyphosate from the water can be obtained with the use of activated carbon, and further to leverage its results, may be used the impregnation of silver and copper on the activated carbon, since the activated carbon in the purest form it is marketed often not sufficiently effective for removing some pollutants. Therefore, this study aimed at the removal of glyphosate by an adsorption process using activated carbon impregnated with $0.5 \%$ silver and $0.5 \%$ copper with the aim of increasing the adsorption efficiency when compared to activated carbon. It was observed that the removal of glyphosate is improved when using the impregnated metal compounds, being $66.1 \%$ with the adsorbent GAC / AgCu and only $21.1 \%$ with GAC. It is still needed profound research related to characterization and adsorption experiments to better explain the adsorption mechanism that occurs in this process. However, it can be concluded that the granular activated carbon soaked with $0.5 \%$ silver and copper developed in the present work may be named as a possible technology for improving the quality of water intended for human consumption for removal of the glyphosate herbicide.
\end{abstract}

Keywords: Activated carbon; Copper; Glyphosate; Silver. 


\section{Introdução}

Junto com o elevado e acelerado crescimento da agricultura, houve uma crescente utilização de pesticidas. (AMARANTE Jr. et al., 2002) A utilização de pesticidas foi intensificada principalmente nos últimos 30 anos, com a chamada Revolução verde e continua crescendo a cada dia.

A preocupação com os efeitos dos pesticidas no meio científico mundial ocorreu logo que eles começaram a ser utilizados, em simpósios de encontros anuais, e várias publicações, porém no Brasil o número de estudos e publicações científicas disponíveis nesta área ainda são restritos (PRATA, Fabio, 2002). Mesmo com as diversas tecnologias e inovações utilizadas na agricultura, os herbicidas ainda são utilizado em grande escala, pelo fato de que a maioria dessas tecnologias não impede o crescimento de ervas indesejáveis.

O herbicida não seletivo mais utilizado atualmente, é o Glifosato, [n-(fosfonometil)glicina], cuja fórmula molecular é $\mathrm{C}_{3} \mathrm{H}_{8} \mathrm{NO}_{5} \mathrm{P}$, representando $60 \%$ do mercado mundial, apresentando uma enorme eficiência contra as ervas daninhas. Há a comercialização de três tipos de glifosato, sendo eles: glifosato-isopropilamônico, glifosato-sesquisódios e glifosato-trimesium. Os dois primeiros citados são comercializados desde 1971 pela Monsanto Corporation com o nome de Roundup, e o último foi patenteado pela atual Syngenta. De todos os defensivos consumidos no Brasil, o Glifosato representa $30 \%$ de todo o volume (AMARANTE Jr. et al., 2002). De modo geral, ele não é metabolizado pela planta, sendo assim a maior parte da concentração do glifosato chega ao solo em sua forma primária (TONI et al., 2006). Por ele não ser metabolizado nas plantas, sua principal degradação é feita por microrganismos, tendo seu principal metabólito o ácido aminometilfosfônico (AMPA).

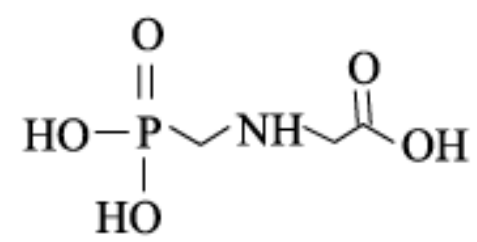

Glifosato

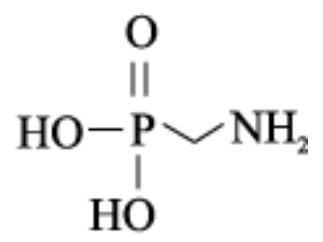

AMPA

Figura 1 - Estrutura química Glifosato e seu metabólito AMPA

Há evidências de o Glifosato ser prejudicial ao ambiente, pela toxicidade ambiental, sua polaridade, alta capacidade de adsorção e a resistência adquirida pelas ervas daninhas após o uso prolongado do mesmo, através da seleção natural (YAMADA, Tsuioshi; CASTRO, C. R. P., 2007). Segundo estudos, a toxicidade deste herbicida é relativamente baixa, porém, componentes de seus metabólitos apresentam maior toxicidade que seu componente ativo, como por exemplo, as etilaminas, encontradas em glifosato comercializado, elas causam sérias irritações tóxicas em peixes, e ainda no sistema respiratório e pele. Em relação a efeitos gerais causados em humanos pelo herbicida, ele pode impedir ações enzimáticas, causar problemas respiratórios, arritmias cardíacas, hipotensão entre outros. Este herbicida é considerado com baixa toxicidade para várias espécies, porém há um efeito em sua teia alimentar, podendo causar até a extinção de espécies. Há o exemplo de uma espécie de sapo, que está em perigo de extinção, por causa da destruição de seu habitat natural, causada pelo Glifosato (AMARANTE Jr. et al., 2002).

A remoção do glifosato da água pode ser realizada por meio do uso do carvão ativado como um adsorvente, segundo estudos ele é um adsorvente comum, muito utilizado no tratamento de água. A eficiência de adsorção de micropoluentes depende das propriedades físicas e químicas do composto, principalmente sua solubilidade em água e o coeficiente de partição da água, sendo uma ótima opção para a remoção do glifosato, sabendo que ele é altamente polar.

O carvão ativado é constituído de materiais carbonáceos microcristalinos de elevadas área superficial específica e atividade química, e pode ser facilmente preparado com materiais de baixo custo (Gonçalves, G. C., et al., 2006), como casca de coco, carvão mineral (antracito, betuminoso e 
lignito), madeiras (de alta e baixa densidade), turfa, resíduos de petróleo, ossos de animais e resíduos agroindustriais. (Cuhadaroglu, D.; Uygun, O. A., 2008)

Novos materiais com maior capacidade adsortiva tem sido estudados, por exemplo, os compósitos à base de carvão ativado com óxidos de ferro sintéticos. Os compósitos também podem apresentar atividade catalítica para diversas aplicações, tais como a degradação de compostos orgânicos, uma vez, que os óxidos de ferro apresentam potencial catalítico. (Tagliaferro, G. V.; et al., 2011)

A água é essencial para todas as formas de vida encontradas na Terra, tendo funções biológicas e químicas, estando presente em diversas substâncias e organismos. Dentro de algumas de suas funções, está o controle da temperatura atmosférica, o transporte de inúmeros compostos para o interior do solo, sendo assim, ela deve ser preservada, minimizando os poluentes, incluindo os pesticidas (FARIA, Leonardo., 2004).

O carvão ativado na forma virgem que é comercializado muitas vezes não é suficientemente eficaz para a remoção de certos poluentes. Para melhorar a sua eficiência pode-se modificar a sua superfície a fim de que suas interações sejam mais eficazes para a adsorção, dentre estas modificações podemos citar a impregnação de metais, que já foi realizada em trabalhos anteriores (YAMAGUCHI, 2013).

Portanto, o presente trabalho visou a remoção do herbicida glifosato por meio de um processo de adsorção utilizando o carvão ativado impregnado com prata e cobre $0,5 \%$ com o objetivo de aumentar a eficiência de adsorção quando comparado ao carvão ativado comercial.

\subsection{Justificativa}

A remoção do glifosato em águas contaminadas é de extrema importância, visto que a água potável está a cada dia mais escassa, e o herbicida está em crescente demanda de utilização, sendo nocivo ao ambiente. Poucos trabalhos foram encontrados que investigam a eficiência desta na redução de compostos mais recalcitrantes aos processos convencionais, como os pesticidas.

De acordo com a Portaria do Ministério da Saúde n 2914 de 12 de dezembro de 2011, que dispõe sobre os procedimentos de controle e de vigilância da qualidade da água para consumo humano e seu padrão de potabilidade, a água para uso doméstico tem que ser potável, ou seja, não pode conter microrganismos patogênicos e substâncias químicas tóxicas e/ou radioativas, acima dos padrões recomendados. Para os agrotóxicos que se encontram em níveis abaixo de $0,5 \mathrm{mg} . \mathrm{L}^{-1}$, devem ser considerados os quais compostos químicos impedem obter uma água de abastecimento, e assim, é necessário fazer um tratamento de modo a reduzir ou minimizá-los sua ação nesta fonte de água. Para o Glifosato os níveis devem estar abaixo de $500 \mathrm{mg} . \mathrm{L}^{-1}$. Portanto, a preocupação com a crescente presença de contaminantes orgânicos como os pesticidas e os seus efeitos sobre a saúde humana, mesmo quando se encontram em baixas concentrações, motivou este estudo.

A aparição destes compostos em águas superficiais, cada vez em maiores concentrações devido a intensificação das atividades agrícolas, tem chamado a atenção e intensificado o desenvolvimento de novas técnicas eficientes na sua redução. Para este estudo foi utilizada a adsorção com carvão ativado, impregnado com prata e cobre $0,5 \%$, com isso, foi esperado desenvolver um tratamento viável na obtenção de água potável, apresentando elevada eficiência na redução dos poluentes orgânicos e inorgânicos, a níveis que atendam as legislações vigentes e apresentem efeitos toxicológicos reduzidos.

\subsection{Objetivo}

O objetivo geral deste estudo será avaliar a eficiência de carvão ativado granular impregnado com prata e cobre $0,5 \%$, no processo de adsorção para a remoção de pesticida glifosato em, apontando-se como uma possível tecnologia para a melhoria na qualidade da água destinada ao consumo humano. 


\section{Material e Métodos}

\subsection{Modificação do Carvão ativado impregnado com Prata e Cobre (GAC/AgCu)}

Para o estudo de adsorção foi utilizado carvão ativado granular (GAC) (Bahiacarbon Agroindustrial Ltda.) obtido da casca de coco de dendê (oil palm ou Elaeis guineesis) com granulometria de $16 \mathrm{X} 52$ mesh e temperatura de ativação de $1200^{\circ} \mathrm{C}$. Este carvão foi selecionado de acordo com os resultados obtidos em trabalhos anteriores (SILVA et al., 2012; SILVA-MEDEIROS, 2012; YAMAGUCHI, 2013). As especificações fornecidas pelo fabricante para o carvão ativado estão disponíveis na Tabela 1.

Tabela 1: Especificações do carvão ativado granular (GAC)

\begin{tabular}{ll}
\hline Características & Especificação \\
\hline Número de iodo $(\mathrm{mg} / \mathrm{g})$ & 885 \\
Densidade $\left(\mathrm{g} / \mathrm{cm}^{3}\right)$ & 0,57 \\
Umidade $(\%)$ & 8,5 \\
Diâmetro médio $(\mathrm{mm})$ & 0,63 \\
Diâmetro efetivo $(\mathrm{mm})$ & 0,42 \\
\hline
\end{tabular}

Para a impregnação de compostos metálicos no carvão utilizou-se a técnica da impregnação úmida, com excesso de solvente, nas concentrações de $0,5 \%$ de cobre e $0,5 \%$ de prata. A escolha do método e das concentrações de metais foi baseada e adaptada da patente "Carvão ativado impregnado com prata e cobre para eliminação de microrganismos da água" (BERGAMASCO, 2010) e nos melhores resultados obtidos em trabalhos anteriores (SILVA-MEDEIROS, 2012; YAMAGUCHI, 2013).

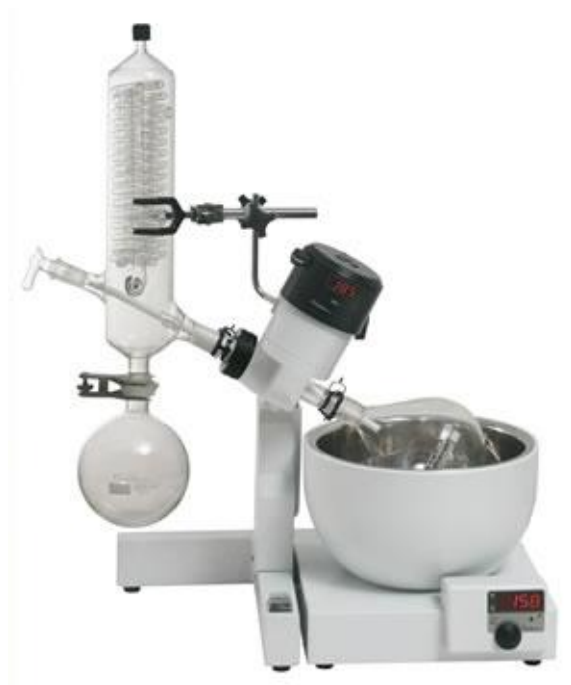

Figura 2. Evaporador rotativo FISATOM utilizado na impregnação do carvão ativado.

A impregnação é realizada em evaporador rotativo, onde são adicionados CAG e água deionizada na proporção 1:1 (m/m) em balão de capacidade de $1 \mathrm{~L}$, e em seguida, nitrato de prata e sulfato de cobre dissolvidos em $30 \mathrm{ml}$ de água deionizada em quantidades necessárias para atingir a 
concentração desejada. Essa mistura permaneceu então sob agitação (40 rpm), à temperatura ambiente por 24 horas. Depois desta etapa, o excesso de água foi retirado utilizando pressão negativa à $60^{\circ} \mathrm{C}$ por $1 \mathrm{~h}$ e em seguida a amostra foi levada para secagem em estufa à $100^{\circ} \mathrm{C}$ por 24 horas.

Após a secagem, o carvão foi submetido ao tratamento térmico em forno mufla a uma temperatura de $300^{\circ} \mathrm{C}$ durante 3 horas. Ao final da etapa da impregnação a amostra foi submetida a uma lavagem a fim de remover os íons metálicos que não foram impregnados, seguida de uma última secagem em estufa a $100{ }^{\circ} \mathrm{C}$.

\subsection{Avaliação de adsorção de Glifosato}

O presente trabalho utilizou água com contaminação artificial que consistiu de água deionizada contaminada com o pesticida Glifosato na concentração de $20 \mathrm{mg} \cdot \mathrm{L}^{-1}$ que foram deixados sob agitação durante $24 \mathrm{~h}$ para garantir o tempo de equilíbrio. Após $24 \mathrm{~h}$ verificou-se a concentração de glifosato a fim de determinar a quantidade adsorvida de glifosato. Todos os ensaios foram realizados em duplicata.

O método selecionado para a detecção da concentração de glifosato em solução foi por meio de cromatografia de íons com detecção condutimétrica, sendo que foi utilizado um cromatógrafo DIONEX modelo DX-500 e uma coluna de troca iônica DIONEX AS18, com concentração de KOH 20 $\mathrm{mM}$ e corrente $50 \mathrm{~mA}$.

\section{Resultados e Discussões}

Os resultados para a remoção de glifosato estão apresentados no Gráfico 1.

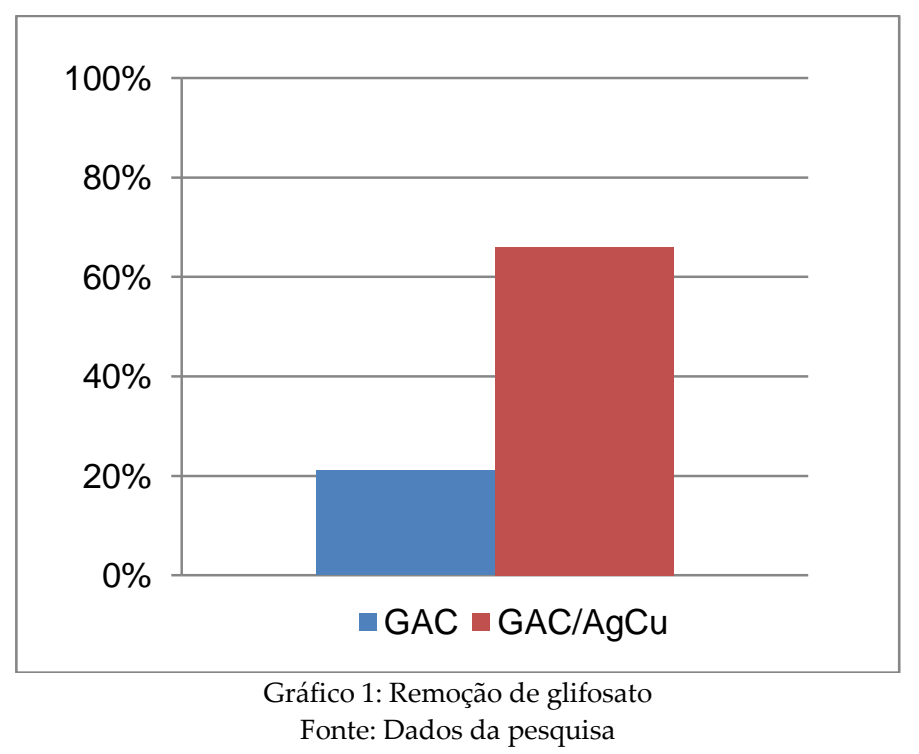

Pode-se notar que a remoção de glifosato é melhorada quando se utiliza a impregnação de compostos metálicos, sendo de $66,1 \%$ com o adsorvente GAC/AgCu e de apenas $21,1 \%$ com GAC. Isto se deve a alteração da superfície do carvão ativo que está possivelmente carregada positivamente, visto que o glifosato tem carga negativa em condições normais. Ainda são necessárias pesquisas mais aprofundadas relacionadas a caracterização e ensaios de adsorção para explicar melhor o mecanismo de adsorção que ocorre neste processo.

6 Conclusões

Com os resultados obtidos pode-se concluir que o carvão ativado por si só não é eficiente para a remoção de glifosato, porém por meio de uma metodologia simples de modificação da superfície obteve-se um resultado promissor. O carvão ativado granular impregnado com prata e cobre $0,5 \%$ 
desenvolvido no presente trabalho apresentou uma alta remoção do herbicida glifosato por meio de adsorção, apontando-se como uma possível tecnologia para a melhoria na qualidade da água destinada ao consumo humano.

\section{Referências}

AMARANTE Jr. et al. Glifosato: Propriedades, toxicidade, usos e legislação. Quim. Nova, Vol. 25, No. 4, 589-593, 2002.

AMARANTE Jr. et al. Métodos de extração e determinação do herbicida glifosato: breve revisão. Quim. Nova, Vol. 25, No. 3, 420-428, 2002.

BERGAMASCO, R. ; NAKAMURA, C. V. ; SANTOS, Onélia Aparecida Andreo dos ; SILVA, Flávia Vieira da . Carvão ativado impregnado com prata e cobre para eliminação de microrganismos da água - PI: 016.100.000.478. 2010.

CUHADAROGLU, D.; UYGUN, O. A. Production and characterization of activated carbon from a bituminous coal by chemical activation. African Journal of Biotechnology 2008, 7, 3703.

FARIA, L. J. S. Avaliação de diferentes sorventes na extração em fase sólida de pesticidas em água. Desenvolvimento e validação de metodologia. 2004. 61 f. Dissertação (Mestrado) - Curso de Química Industrial, Unicamp, Campinas, 2004.

GONÇALVES, G. C.; MENDES, E. S.; PEREIRA, N. C.; SOUZA, J. C. Produção de carvão ativado a partir de bagaço e melaço de cana de-açúcar. Acta Science Technology 2006, $28,21$.

PRATA, F. Comportamento do glifosato no solo e deslocamento miscível de atrazina. 2002. $149 \mathrm{f}$. Tese (Doutorado) - Curso de Agronomia, Escola Superior de Agricultura Luiz de Queiroz, Piracicaba, 2002.

SILVA, F. V.; YAMAGUCHI, N. U.; LOVATO, G. A.; SILVA, F. A.; REIS, M. H.; AMORIM, M. T.; TAVARES, C. R.; BERGAMASCO, R. Effects of coconut granular activated carbon pretreatment on membrane filtration in a gravitational driven process to improve drinking water quality. Environ Technol, v. 33, n. 4-6, p. 711-6, 2012.

SILVA-MEDEIROS, F. V. Desenvolvimento de Materiais Filtrantes a Partir da Modificação de Meios Porosos para a Melhoria da Qualidade da Água Destinada ao Consumo Humano. 2012. Tese (Doutorado em Engenharia Química). Universidade Estadual de Maringá, Maringá, Paraná, Brasil. 2012.

TAGLiAfERRO, G. V.; PEREIRA, P. H. F.; RODRIGUES, L. A.; SILVA, M. L.C. P. Adsorção de chumbo, cádmio e prata em óxido de nióbio $(\mathrm{V})$ hidratado preparado pelo método da precipitação em solução homogênea. Química Nova 2011, 34, 101.

TONI et al. Adsorção de glifosato sobre solos e minerais. Quim. Nova, Vol. 29, No. 4, 829-833, 2006.

YAMADA, T.; CASTRO, C. R. P. Efeitos do glifosato nas plantas: Implicações fisiológicas e agronômicas. International Plant nutrition institute, Informações Agronômicas, № 119 SETEMBRO/2007.

YAMAGUCHI, N. U. Filtro híbrido de carvão ativado e membrana para purificação da água de consumo humano. 2013. Dissertação (Mestrado em Engenharia Química). Universidade Estadual de Maringá, Maringá. 2013. 